\title{
Considering the temperature factor of hardening concrete in the construction of transport infrastructure facilities
}

\author{
Sergey Pulyaev ${ }^{1 *}$ and Ivan Pulyaev ${ }^{2}$ \\ ${ }^{1}$ Moscow State University of Civil Engineering, Yaroslavskoe shosse, 26, Moscow, 129337, Russia \\ ${ }^{2}$ Limited Liability Company "Central Laboratory of Engineering Thermophysics", Eniseyskaya, 7, 3, \\ 1, Moscow, 129344, Russia
}

\begin{abstract}
Currently, there is a significant increase in personal and commercial road transport in the Russian Federation, which is why the issue of building new roads, bridges, tunnels, and other crossings is becoming more acute. Since often during the construction of these facilities, one of the main tasks is to minimize the construction period of the object, the process of intensifying production processes comes first. Based on the fact that the absolute leader in the use of reinforced concrete as the main building material, it is important and necessary to observe all the quality characteristics of this material both at the stage of laying the concrete mixture in the formwork, and in the process of maintaining the hardening concrete until the termination of heat-and-humidity care for it. In this regard, in order to optimize the temperature factor of hardening concrete in the construction of transport infrastructure facilities, it is necessary to provide measures at the design stage to consider the influence of the temperature gradient of hardening concrete on the operational properties of building structures. The article presents the main methods for considering the temperature factor of the hardening concrete of the constructed structures, developed by the authors of the work, the use of which will ensure the defect-free concreting of objects, including in an accelerated time.
\end{abstract}

\section{Introduction}

The modern world is difficult to imagine without road and rail transport. New roads, bridges, overpasses, and interchanges are being built everywhere. Among the leaders in the number of transport facilities introduced in the world is our country. In the Russian Federation, a number of major facilities have been built in recent decades, including the bridge on Russky Island, the Crimean Bridge, the Olympic facilities in Sochi, large construction sites in Moscow, St. Petersburg, and other regions. The construction of many structures is still ongoing, and many are only being designed or planned for construction in the coming years. This is also due to the fact that the number of personal and commercial vehicles in Russia has increased several times in recent years, the development of large cities and megacities is impossible to imagine without the metro, and the connection between cities - without highways and railway crossings. The construction of these objects most often occurs either in rough terrain or in complex urban development, where builders,

* Corresponding author: ivanes50@mail.ru 
along with the need to build objects in complex geological, hydrological and geodetic conditions, must comply with another important criterion - time. The key is to observe requirements for ensuring the high-performance properties of structures in connection with which the fore the issue of accounting for temperature factor of hardening of concrete during the construction of transport infrastructure in an accelerated time frame.

\section{Methodology}

The current experience in the construction of transport facilities for various purposes shows that to account for and control the temperature factor of hardening concrete, there are quite a lot of different methods aimed at obtaining structures of the required quality $\left[\begin{array}{lll}1 & \ldots & 4\end{array}\right]$. At the same time, however, there are a number of fundamental differences from the construction method used, depending on the construction technology of the object, the conditions and pace of construction, the requirements of the customer, and others. But at the same time, an important principle remains the structural assessment of the object (its massiveness, the combination of structures of different sizes and volumes with each other, design solutions), and, as a result, the prediction of the temperature hardening of concrete over time. In this regard, analytical (general scientific) methods of solving the issues raised were used during the work, including modeling the processes occurring in hardening concrete, and conducting full-scale (experimental) studies on a specific construction object [5 ... 7].

Mathematical modeling of processes was carried out using the calculation and analytical complex "ZA", developed at the Research Institute of Transport Construction on the basis of the method of hydraulic analogies, previously proposed by prof. V. S. Lukyanov and A. R. Solovyanchik [ 8 ... 11], and improved by the authors of this work. This complex has a design program that allows you to consider the object under study (grillage, bridge support, span structure, tunnel bottom, overlap, spacer beams, etc.) from the point of view of changing the temperature gradient and strength gain in it in a given period of time. In this case, the study area is divided into a certain number of elements, after which their interaction with each other is considered. This program allows you to predict the behavior of concrete from the point of view of the thermodynamics of technological processes occurring in it, and on the basis of the development of the work project, take measures to optimize the temperature factor of hardening concrete in order to reduce the risk of defects and cracks in structures both at the stage of its heating and at the stage of cooling. This software package was repeatedly tested by comparing the calculated values of the temperature and strength of the hardening concrete and the data on full-scale measurements obtained on a real construction site, including those carried out in extreme temperature conditions.

Full-scale (experimental) studies were carried out on specific construction sites and included testing the developed solutions, monitoring the processes occurring in the hardening concrete, taking (if necessary) measures to prevent the appearance of temperature cracks in the process of concrete aging by measuring and considering the temperatures of the hardening concrete and the outside air.

\section{Results and discussion}

Let's consider the main structural elements of transport structures. It is known that bridge structures most often consist of the supporting part of the structure and the bridge span, tunnel structures include the base (bottom), walls and ceilings, as well as additional structural elements. Experience in the construction of all structures of this type shows that 
even at an early stage of heating the concrete mixture and its transformation into concrete stone, temperature cracks can form in the structure, caused, among other things, by an underestimation of the own thermal stress state of the concrete. This poses a complex problem for the builders, the solution of which is an important and difficult task. Considering the wide variety of transport structures constructed in modern bridge and tunnel construction, this problem must be solved step by step and comprehensively, linking it with the technology of construction of concrete and reinforced concrete structures.

One of the first tasks that must be solved in the construction of structures made of monolithic reinforced concrete is the breakdown of structural elements into grippers along the height of the structure and concreting blocks along its length. And if the breakdown is on the hook height in most cases regulated by factors such as the size of formwork boards design, the pressure of the fresh concrete mix at them, the height of the free drop of concrete, reinforcement design and the main criterion for evaluating the quality of construction from the position of cracking is the correlation between temperature of the base, which fits on the concrete, the temperature of the concrete mix, which the authors said earlier $[12,13]$, and the value of the underlying strength of the base, then, when developing technical documentation within the framework of the project of production works, the greatest questions arise when determining the optimal value of the length of the concreting block, at which it will not form temperature cracks.

In compliance with the requirements of regulatory documents on the permissible temperature difference between the laid concrete and the base, the size of the concreting block in the area of the structure pinching into the base should not exceed $20 \mathrm{~m}$. At the same time, due to the use of some technological techniques aimed at reducing the value of temperature stresses, the size of the concreting block in the pinching zone can be increased to $23 \mathrm{~m}$. When the blocks are pinched on both sides without taking special measures, the size of the concreting block should not exceed $17 \times 17 \mathrm{~m}$. This is caused by the peculiarities of the hardening of the concrete mixture and its transformation into a stone-like state and was described in detail earlier. Unfortunately, at present, this factor has not yet been properly reflected in the regulatory documentation, and given that the distance between temperature-shrinkage joints in precast reinforced concrete structures of transport and pedestrian tunnels can be taken to be up to $40 \mathrm{~m}$, the experience of building a large number of tunnel-type transport structures shows that with the specified value of the distance between the seams, there is a need to break the tunnel bottom into two concreting blocks, and walls and floors erected in the traditional (not "Milanese") way - into three. At the same time, in order to intensify the construction process, the simultaneous arrangement of concreting blocks in a staggered order is allowed. At the same time, blocks №1 and №4 are first concreted (diagonally), and after heating the previously concreted blocks from the exothermy of the cement and its cooling to a temperature of $+20 \ldots 25^{\circ} \mathrm{C}$, blocks №2 and №3 are concreted (Figure 1).

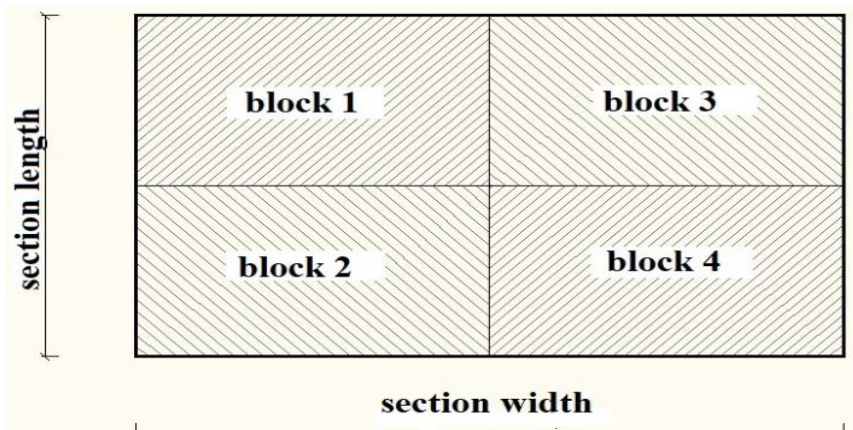

Fig. 1. Diagram of the breakdown of the bottom (overlap) of the tunnel into concreting blocks 
Experience in the construction of large bridge crossings [14] (across the river Oka on the bypass of the city of Murom, across the Volga River on the highway N. Novgorod Vyazma - Kirov to Nizhny Novgorod region, part of the southern section of the Western high-Speed Diameter from the Transport interchange at the intersection with the Ring road around St. Petersburg, the Crimean bridge and others) showed that in order to avoid thermal cracking of ectothermy cement large size design of the bridges also need to be split into blocks of concrete in length with a block size of not more than $17 \mathrm{~m}$ in connection with the "pinched" design of pile raft Foundation, body support - the design of the pile cap accordingly. In this regard, the necessary requirement to ensure the crack resistance of bridge crossing structures is the breakdown of the support elements, as one of the options, into three blocks (two extreme and middle of variable thickness from 1 to $1.5 \mathrm{~m}$ ) or into two concreting blocks. The approximate scheme of the structure breakdown into three concreting blocks (Figure 2) proved to be effective in the construction of large-sized cablestayed grillages and other bridges in Moscow, Rostov-on-Don, Nizhny Novgorod, Sochi and other cities.
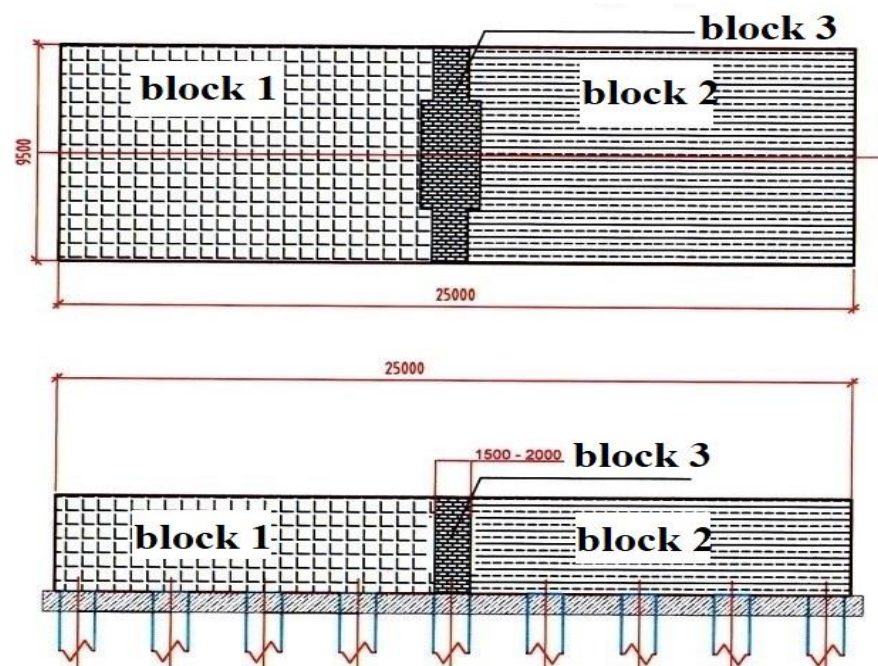

Fig. 2. Approximate layout of the structure of the grillage support into three blocks of concreting

In addition, it allows, firstly, to avoid the appearance of temperature cracks when heating concrete from the exothermy of cement, and secondly, to erect both large blocks simultaneously or almost simultaneously without waiting for the previously erected block to cool down to a temperature that allows concreting the subsequent block. When dividing structures into two concreting blocks, block №1 is first concreted, and after heating the concrete of block №1 from the exothermy of the cement and its cooling to a temperature of $+25 \ldots 30^{\circ} \mathrm{C}$ block №2 is being concreted. With such a breakdown of structures, the consumption of the formwork is somewhat reduced, but the terms of concreting the element itself are significantly extended. To ensure reliable joint operation of all the structural units, however, it is necessary to design the installation of additional periodic profile fittings. Additional fittings must be designed to be embedded in the blocks for at least $1.5 \mathrm{~m}$.

At the same time, the size of the concreting block can be calculated in a slightly different way when constructing spans of bridge structures $[15 \ldots 17]$. Experience shows that with a competent and well-planned, including logistics, process of construction of the object, it is possible to install a seamless block of concreting the span of the bridge crossing in one step with a length of up to $180 \mathrm{~m}$. This experience was implemented during the 
construction of a bridge span over the Moscow Canal in the area of the Khimki region near Moscow.

Another reason for cracking due to temperature influences in the hardening concrete of reinforced concrete structures is the excess of the actual temperature differences when the concrete is maintained in relation to the permissible values. At the same time, both some differences and others depend on many factors and can be regulated when taking special measures. However, these measures to regulate temperature differences during concrete hardening, considering the creation of a favorable internal thermal stress state that increases the crack resistance of structures, can only be carried out on the basis of thermophysical calculations that allow the method of successive approximation (due to changes in heat exchange conditions) to achieve the optimal level of temperature differences, at which the absence of cracks will be ensured. Methods for preventing the appearance of cracks can be different. Currently, the most developed method of regulating the value of temperature differences by changing the thermal resistance of thermal insulation.

When performing thermal calculations is determined by the maximum temperature of heating the hardened concrete and the magnitude of temperature changes by array design, is needed to determine its compliance with the requirements to ensure crack resistance, frost resistance, water resistance and strength of concrete. Calculations are performed at different temperatures stacked concrete mix, while maintaining the concrete at different ambient temperatures in the mold with heat resistance-Millenium $\mathrm{R}=0.3 \mathrm{~m}^{2} \mathrm{~h} / \mathrm{C} / \mathrm{kcal}$, provided that the top surface of the concrete laid one layer of the film, one layer of covering material thickness of $3 \mathrm{~mm}$ and one layer of foil to ensure the required conditions, aging of concrete, as well as providing a thermal resistance of thermal insulation $\mathrm{R}=0.3 \mathrm{~m}^{2} \mathrm{~h} / \mathrm{C} / \mathrm{kcal}$. During the calculations, the required cement consumption is set and the required conditions for maintaining the concrete structure are set.

Consider the construction of a massive grillage support bridge over the Volkhov River, built of concrete class B30 (Figure 3). The calculation program "ZA" allows you to calculate half of the structure when performing calculations of structures of the correct shape, while the calculated values obtained are mirrored from the central axis of the structure set in the program, while obtaining the result of calculating the entire structure. Temperature graphs (figure 4) and strength (figure 5) hardening of concrete at the relevant temperature (temperature of the concrete mix $-15^{\circ} \mathrm{C}$, outdoor air temperature is $-15^{\circ} \mathrm{C}$, the temperature of the underlying base $-15^{\circ} \mathrm{C}$ ) show the corresponding changes depending on the conditions of incubation concrete into the formwork. 


\begin{tabular}{|c|c|c|c|c|c|c|c|c|c|c|c|c|}
\hline$R=1.0$ & $0 \mathrm{~m}^{2}$ & ${ }^{\circ} \mathrm{C}$ & & & & $=0$ & C & & & & & \\
\hline & 1 & 2 & 3 & 4 & 5 & 6 & 7 & 8 & 9 & 10 & & 12 \\
\hline ] & 13 & 14 & 15 & 16 & 17 & 18 & 19 & 20 & 21 & 22 & 2 & 24 \\
\hline 르 & 25 & 26 & 27 & 28 & 29 & 30 & 31 & 32 & 33 & 34 & 3 & 36 \\
\hline$\stackrel{\|}{\simeq}$ & 37 & 38 & 39 & 40 & 41 & 42 & 43 & 44 & 45 & 46 & 4 & 48 \\
\hline & 49 & 50 & 51 & 52 & 53 & 54 & 55 & 56 & 57 & 58 & 5 & 60 \\
\hline ? & 61 & 62 & 63 & 64 & 65 & 66 & 67 & 68 & 69 & 70 & 7 & 72 \\
\hline & 73 & 74 & 75 & 76 & 77 & 78 & 79 & 80 & 88 & 82 & 8 & 84 \\
\hline
\end{tabular}

Fig. 3. Design scheme of the support grillage

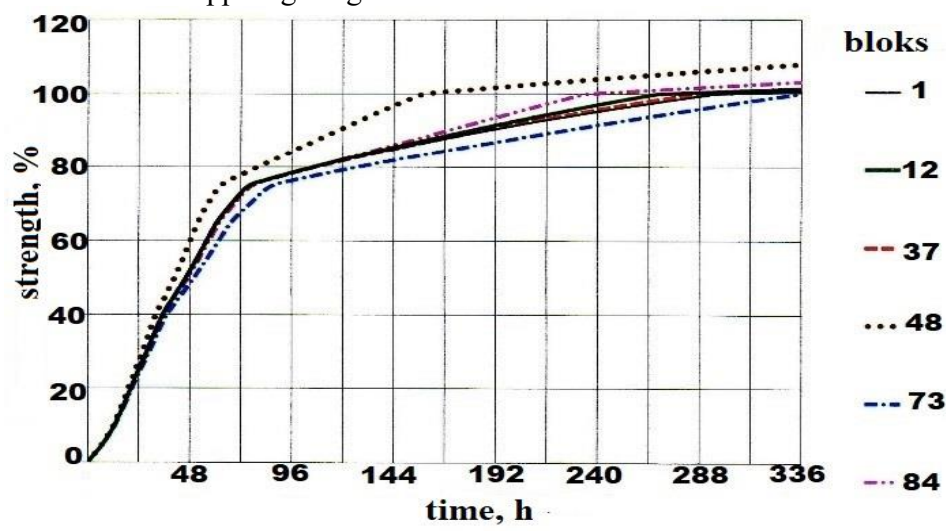

Fig. 4. Graph of the temperature

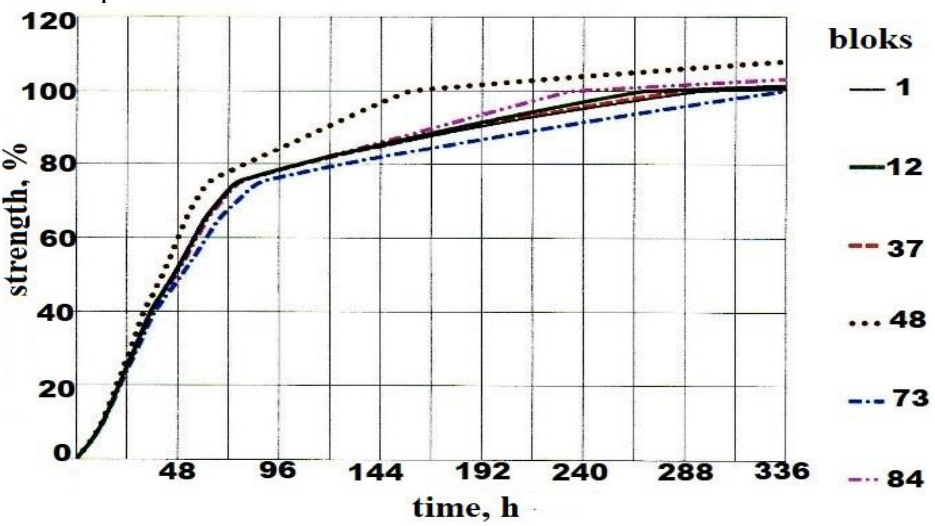

Fig. 5. Strength gain graph

The presented graphs show that the most vulnerable from the point of view of crack formation are the extreme faces of the grillage (blocks №1 and №12), as well as the contact zone of the laid concrete mixture with the base of bored piles (blocks №73 and №84). The 
main cause of cracking due to temperature influences in the hardening concrete of reinforced concrete structures is the excess of the actual temperature differences when the concrete is maintained in relation to the permissible ones. At the same time, both some differences and others depend on many factors and can be regulated when taking special measures. This is due, among other things, to increased heat removal in areas with the greatest contact of low-mass faces and edges of the grillage with the environment, which has a deliberately lower temperature in relation to the massive core of the grillage, and a colder natural base consisting of soil and a metal base, which indicates that in these places (taking into account the formation of a favorable thermal stress state of hardening concrete), it is necessary to increase the thermal resistance of thermal insulation, which protects the concrete mixture from rapid cooling, and, as a result, the laying of additional layers of thermal insulation material. At present, this method of regulating the magnitude of temperature differences is the most developed and has shown its effectiveness in practice due to repeated testing on objects of various massiveness built in different regions of our country.

The obtained research results and many years of experience in scientific support of the construction of transport infrastructure facilities allowed us to draw conclusions, according to which, regardless of the construction technology of the object, the materials and methods used, in the practice of conducting concrete works, it is possible to choose options for the construction of structures that, by taking into account the temperature factor of hardening concrete, will ensure At the same time, an important task that needs to be solved at the stage of developing technical documentation is the task of taking into account the temperature factor of hardening concrete before starting construction work on the object. It is also important to address the issue of reflecting the factors described above that affect the crack resistance of the structure in the regulatory and technical documentation. The main purpose of this is to ensure the production of defect-free concrete structures with high performance characteristics already at the design stage of non-class facilities.

\section{Acknowledgments}

The authors express their gratitude to the General Director of the Central Laboratory of Engineering Thermophysics LLC, V. V. Passek, for his help in writing this scientific work.

\section{References}

1. V.V. Passek, V.V. Zakovenko, E.A. Antonov, A.N. Efremov, Scientific works of JSC TSNIIS, 213, 73-75 (2002)

2. E.A. Balyuchik, K.D. Cherniy, Scientific works of JSC TSNIIS, 257, 49-57 (2010)

3. A.V. Gizburg, Scientific and technical journal «Vestnik MGSU», 1, 98-110 (2014)

4. H. Zhu, Y. Hu, Q. Li and R. Ma, Construction and Building Materials, 244 (2020)

5. A.R. Solovyanchik, S.A. Shifrin, S.B. Sokolov, Scientific works of JSC TSNIIS, 217, 180-188 (2003)

6. A.I. Vasilyev, S.G. Veitsman, Scientific-technical journal "Bulletin of bridge building», 1, 2-17 (2015)

7. J. Xin, G. Zhang, Y. Liu, Z. Wang and Z. Wu, Construction and Building Materials, 21, 381-390 (2018)

8. A.R. Solovyanchik, Scientific works of JSC TSNIIS, 105, 12-30 (1989)

9. V. G. Petrov-Denisov, V. N. Gordeeva, S. A. Shifrin, A. I. Li, Scientific and technical journal " Concrete and reinforced Concrete», 1, 45-51, (1992) 
10. A. M. Tarasov, F. Yu. Bobrov, D. V. Pryakhin, Scientific-technical journal "Bulletin of bridge building», 1, 21-27 (2007)

11. J. Wu, X. Liu, H. Wu, L. Li and Z. Liu, Journal of Testing and Evaluation, 48(4) (2020)

12. I.S. Pulyaev, S.M. Pulyaev, Scientific and technical journal «Vestnik MGSU», 2, 295304 (2011)

13. C. Machelski and M. Pustelnik Proceedings of the fib Symposium 2019: Concrete Innovations in Materials, Design and Structures, 1461-1468 (2019)

14. A. F. Kamendrovsky, Scientific-technical journal "Bulletin of bridge building», 3-4, 24-29 (2003)

15. S.B. Sokolov, Scientific works of JSC TSNIIS, 213, 167-172 (2002)

16. T. Z. H. Ting, M. E. Rahman, H. H. Lau, M. Z. Y. Ting, «Construction and Building Materials», 201, 763-777 (2019)

17. X. Chen, Z. Liu, S. Guo, Y. Huang, W. Xu, «Construction and Building Materials», 205, 10-20 (2019) 